\title{
Analysis on the Practicalities of Economic Strategies Government Implemented During and After the Coronavirus Pandemic
}

\author{
Hanning Cao \\ The High School Affiliated to Renmin University of China, Beijing, 100080, China \\ Email:vivian.wang@cas-harbour.org
}

\begin{abstract}
This analysis was promoted during the global devastation of coronavirus. Since official administration was launching a variety of economic strategies because of the existence and destructiveness of COVID-19, it's compulsory and emergent for citizens to understand whether these policies are absolutely accurate and considering. This paper classified economic tactics utilized under this general timeframe into two categories, one discussing solutions implemented for facing pandemic directly, and the other analyzing the process recovering from this tragic incident. The basic idea which undergrounds the research procedure of this passage goes to collecting various data, utilizing comprehensive investigating methods, and taking both physical and philosophical factors into considerations. Briefly, the result of this paper is that current governmental strategies should be further analyzed from more representative perspectives, being guaranteed by more physical regulations, and put more attention to the sustainability of general society.
\end{abstract}

Keywords: Economic strategies, coronavirus pandemic, economy recovery, carbon emission

\section{INTRODUCTION}

The coronavirus epidemic was devastating worldwide economic statuses. According to professor Erin Duffin, the global gross domestic production rate will inevitably suffer declines for at least 2.4 percent over 2020 [1]. However, unfortunately, demands and supply shocks for medically living necessities were evolving negatively, aggregated substantially. Consequently, previous macroeconomic tools implemented by governments were deemed insufficient to provide concert supports for vulnerable patients, overwhelming physicians, and general populations. In order to reverse these tragic situations, national governments would have to enforce and impose much more caring and comprehensive regulations. Analyzing policies that might stimulate economic capacities to become truly vital since the relentless impacts of coronavirus are increasingly unbearable. As a result of realizing that the consequences above might happen, this paper will primarily analyze the alternatives and solutions that have somehow got the capability of resolving these dilemmas. Purposes of editing this essay include theoretically evaluating trustworthiness and objectively discussing the practicality of constructing seemingly reasonable options into actual society. For the following passage, the principle line will be developed dividing by two different timeframes_- the process of eliminating disease, and the process of recovering from the disease. While data utilized in the following paragraphs were majorly adapted from the calculations by technological means, objective predictions provided by authoritative and trustworthy resources, and relative psychiatric experiments. Thus, a comprehensive analysis system was forged, containing sufficient coverages and relatively high credibility.

\subsection{Structure}

In order to forge more logical and ample deductions, the following passage will discuss from two perspectives.

Mainly separating basing on timeframe level.

Overall economic approaches are distinctive between the eliminating stage during the epidemic and the recovering stage from the depressions.

Thus, the logical sequence implied in this paper follows the progression of time. Recalling from the outbreak of COVID-19, mentally extend along with the development of disease prohibition, continuing until the termination of period consisting of high infecting probabilities, and deeper deliberating the recovering procedure of the world economy.

\subsection{Overview}

March 20, 2020, "Bard of American Theater", four-time Tony Award-winning playwright, Terrance McNally, tragically died because of complications of the coronavirus, setting crowds inconsolable. He was not an exception, over 200,000 vulnerable Americans died because of infections caused by the coronavirus [2]. Medical deficiencies were soon realized as factors that forged this problem. Thus, the government started to 
purchase and found more medicate systems and public infrastructures in order to defeat the pandemic.

Consequently, since there are enormous demands of generating qualified remedial infrastructures during this tough period, currently, a variety of new governing strategies have been taken into practice.The practicality and comprehensiveness of those tactics remain questionable.
Figure 1 approximately reveals actual economic impacts caused by coronavirus.

Figure 2 shows Fangcang shelter hospital patient flows during the coronavirus disease 2019 outbreak in Wuhan, China

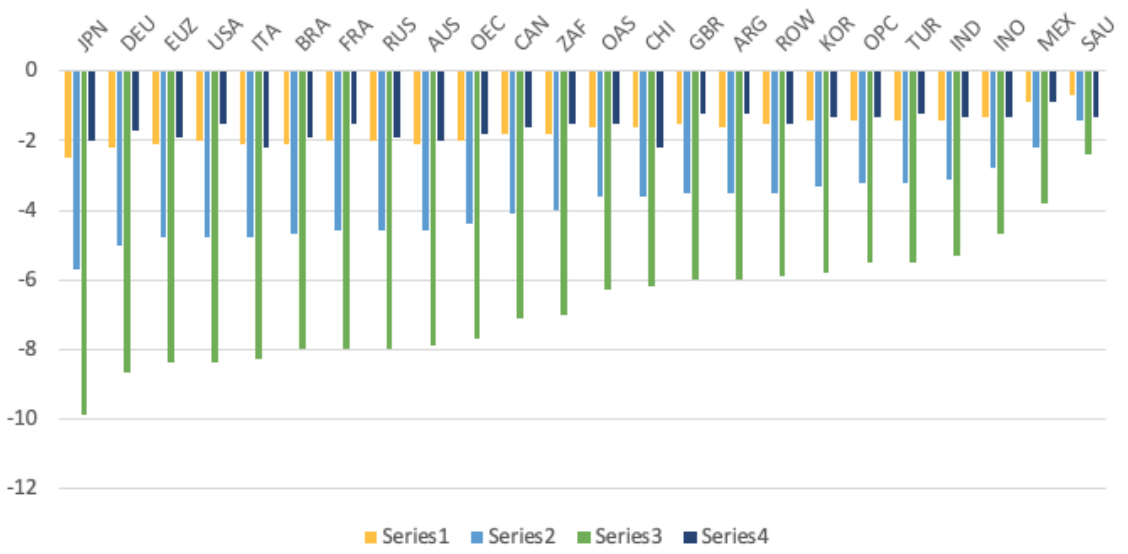

Figure 1 GDP loss in 2020[14]

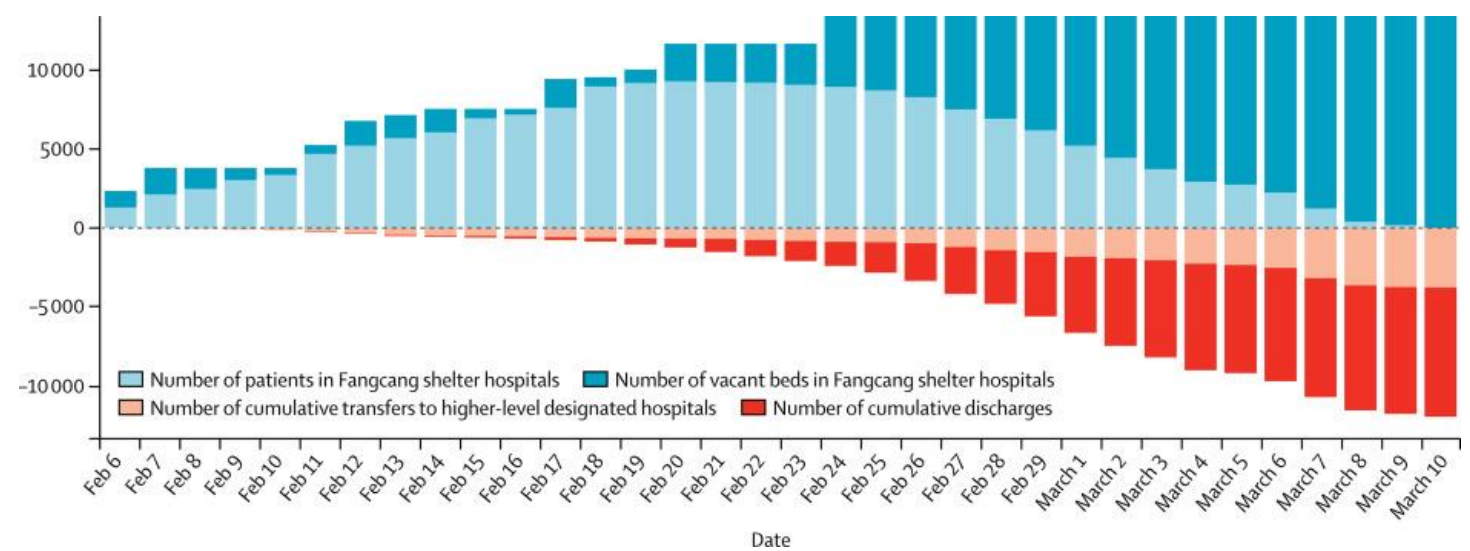

Figure 2 Revelation of the emergent needs for medical infrastructures [15]

\subsection{Elimination Process}

\subsubsection{Example (Defense Production Act) from the United States}

Starting from prohibition procedures, simultaneously with the occurrence of coronavirus, the United States funded extensively on the activation of the Defense Production Act, which ensures and warrants citizens' basic living necessities through regulatory means elevating manufacturing efficiency. However, as John Grady [3] states, launching this act delivers a message that "you're obligated to produce", regardless of potential risks firms might encounter and crises that labors might be suffering unbearably during the process of achieving higher production goals.
Utilitarianism is an ethical theory that determines and judges right and wrong by focusing solely on the outcome. It's a form of consequentialism [4]. According to Santa Clara University [5], utilitarianism contains possibilities of being unjust, because incidents that benefit society the most are not always moral and just. Utilitarianism and consequentialism only consider results but are neglecting these invisible obstacles on procedures. Proposals which were lack of considerations were always incongruous to be applied in reality.

\subsubsection{Example (SURE - Support Mitigating Unemployment Risks in Emergency) from Europe}

Moreover, the European Commission recently proposed a policy, "SURE - Support Mitigating Unemployment Risks in Emergency", aiming at redirecting social structural 
funds to better accommodate the enormous demands required by current citizens. Although temporary investigations are deficient to demonstrate the sustainability of this motion, recent data provided by European Governments forcefully illustrated that under contemporary circumstances, legislating this assumption provided giant amounts of financial support for European countries, up to 100 billion euros, and it was predicted to grow the European economy by at least $6.1 \%$ within a year time, bringing huge recoveries for general European economic status. [6]

\subsection{Innovative "inspiration" __ Regulating Carbon Emission}

Professor Mountford argued that restricting carbon emissions may substantially diminish the negative impacts coronavirus brought to susceptible patients who were previously suffering from respiratory diseases. The basic mechanism behind this contention mainly indicates the truth that excessive carbon emission impacts on human physical states as much as coronavirus does. For instance, carbon dioxide arises overall temperature, and high temperature contains possibilities of triggering asthma [7], a typical respiratory symptom, quoting from the World Health Organization, which might potentially affect 300 million people.

In addition, the United Nations listed constructing "sustainable cities and communities" as one of the most important developmental goals that have to be fulfilled within the 21 st century. Sustainability is extremely vital in conducting actual economic decisions. When striving for high productivities and pursuing profound outcomes, we have to consider the promotion of human ethical and environmental processes. Linking back to nowadays epidemic background, scientists thus regard the cessation in pollution and manufacturing caused by coronavirus as an "opportunity to accelerate the inevitable shift to low-carbon and increasingly affordable energy and transport systems that will bring long-term economic benefits"[8]. Lower emission means less pollution and eliminating pollution means better protection for infected individuals, as well as for those who are bearing high risks to be infected.

For short term perspective, permitting and implementing less polluting industries provide protective safeguards for people who are lack of immunizing capacities to maintain healthy bodily status.

Contrariwise, for a relatively long timeframe, essentially improving natural and artificial environments increases the sustainability of mankind. Although there are voices negating, saying that restrictions on factories may to some extent decrease productive efficiencies, this concern can't even stand. According to Paul L. Poirot,

the term property has no significance except as it applies to something owned by someone. Comparing valuable human lives, which are compulsory, with vague numbers, which are additional, is definitely not an efficient tradeoff, human dignities and living standards should always be prioritized regardless of the uniqueness of social contexts.

Surprisingly, the World Resources Institute also claims that happening this transition may even boost the economy as well. Since the construction and popularization, of compulsory infrastructures required for practicing novel resource allocations, and environmental cognition, need the involvement of human. Deciding to launch this inspiration will generate enormous amounts of job opportunities, and more people taking jobs improves the overall output of global productions. Thus, restricting carbon emission inevitably elevates the world's economic status.

As one of the earliest countries that decided to adapt carbon emission regulatory resolutions, Germany has experienced a skyrocket in its efficiencies of pollution reduction, which can somehow be utilized as reference and thus be popularized across the globe.

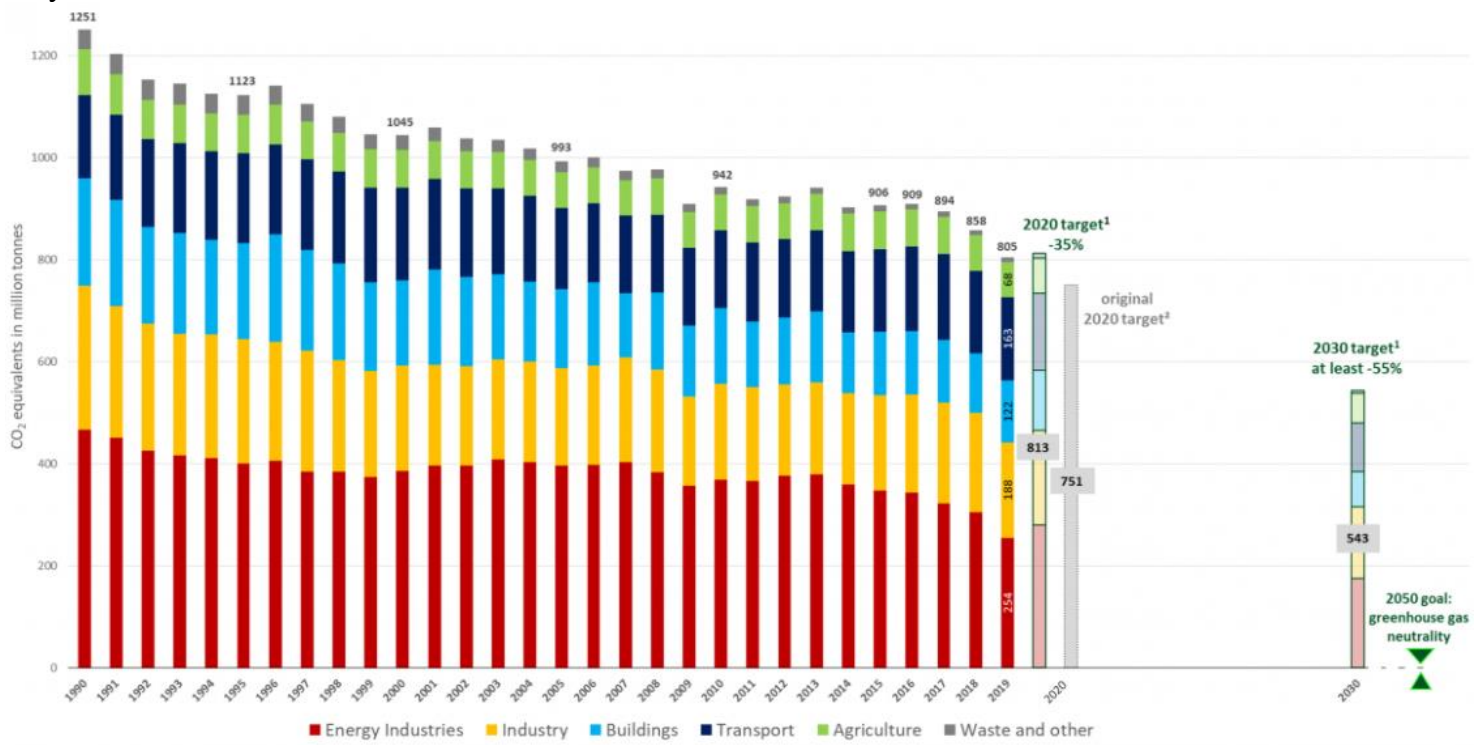

Figure 3 Reduction in Germany's greenhouse gas emissions and illustration of its energy transition targets [16] 


\subsection{Further Discussion}

Critically connecting these three strategies synchronously. Empowering commissions and governments to issue capital markets, financial assistance and humanized services acquired higher possibilities to be practiced. Tightly binding labor markets with policy-amendatory institutions, it's undebatable that laborers and workers are very likely to be given more careful attention, as well as considerations containing higher comprehensiveness by major populations. Unfortunately, at the current stage, giving governments sublime rights may be not the best choice since the administration's tactics were not absolutely accurate. Thus, certain regulations were necessary and needed to be kept.

Furthermore, with regard to the continual human process, economists have to consider about both economic benefits and sustainability of human society when proposing treatment schemes.

Consequently, for the sake of fulfilling citizen's fundamental living necessities, it's both compulsory and extremely vital to improve, publicize this category of ideas and thus generate higher probabilities to benefit the whole society.

\subsection{Recovery Process}

\subsubsection{Current problems}

Respectively, caring about the salvage process from the Cov-19 epidemic, the existence of governments is to promote the formation of more reliable and beneficial administrating tactics for general populations. To start with, one of the most seemingly acceptable stratagems is to permit workers returning to their careers and started conducting necessities which they are assigned. However, although this proposal appears to be extremely hummable and socially beneficial, it's neglecting the truth that under most circumstances, employees healthy can't be sufficiently protected from those invisible underlying risks related to coronavirus. Retrieving from the mathematical model assumed by investigator Simpson, in a country the size of Britain or Italy, there are more than 40,000 new infections every day if citizens still maintain their behaviors the same as days when the coronavirus hasn't outbreak [9]. The medical department of Harvard University has already proved that quarantines and social distancing are the most efficient solutions that will prohibit the widespread and dissemination of coronavirus [10]. In current situations, disobeying accurate scientific results will probably cause irreversible impacts, infection of diseases, even unnecessary deaths of vulnerable and innocent living individuals. While, even standing on the viewpoint of economist, losing workforces are definitely disadvantageous with regard to economic states.

\subsubsection{Valid solution}

Instead of setting citizens "naked" toward potential dangers, there are several conceptions arguing that coronavirus periods can actually be viewed as opportunities to digitize working and completely shift present consuming preferences into online transactions. According to MIT 2013, online shopping has already become the eco-friendliest market, having comprehensive safeguards [11]. There are less necessary inputs and taxes for online transactions. In a nutshell, publicizing online commercial interactions is providing a better alternative to replace and complement hibernal shopping systems, citizens have to be provided the rights of deciding their own living styles, the rights of deciding their own life; markets will inevitably shift gradually into more efficient and practical phases.

\section{CONCLUSION}

Throughout the whole passage, discussions mainly contain close observations of the economic strategies utilized under current overall social circumstances. As illustrated in the introduction section, since coronavirus was forcefully damaging general productive efficiencies and human living qualities, governments were partially obligated to reconsider their coping economic means. For both the United States and Europe, the primary economic tools adopted were lack of well-rounded evaluations from every possible perspective. In order to promote the pace of developing a city consisting of impressive sustainability, administrations might have to attempt novel environmental-friendly proposals, such as the restrictions on carbon emission. While, building the most considering resolution requires decision-makers to combine and improve these assumptions simultaneously, setting the prosperity of all humanities as the main purpose, and devote their entire passion.

However, this paper contains restrictions, it's not providing enough predictions related to the pandemic's potential impact of the future market, which can be consummated in further investigations.

\section{ACKNOWLEDGMENT}

This paper is the crystallization of ambition and endeavors. I truly appreciate the academic guidance provided by professor Frank Lichtenberg, who built my fundamental academic cognition about health economics; the assistance of writing tutor Eva Chen, she taught me the basic structures and points needing attention related to academic papers; the universities and institutions that released their experimental results on the internet. 


\section{REFERENCES}

[1] Statista. 2020. COVID-19: Percent Change In GDP By Country 2020 | Statista. [online] Available at: <https://www.statista.com/statistics/1102991/covid-19percent-change-gdp-country/> [Accessed 10 October 2020].

[2] Hipes, P. and Hipes, P., 2020. U.S. Coronavirus Update: America Now Has Over 7 Million COVID-19 Cases - Deadline. [online] Deadline.com. Available at: $<$ https://deadline.com/feature/coronavirus-deaths-unite d-states-1202874446/> [Accessed 10 October 2020].

[3] Grady, J., 2020.John Grady, Author At USNI News. [online] USNI News. Available at: <https://news.usni.org/author/jgrady> [Accessed 29 September 2020].

[4] Ethics Unwrapped. 2020.Utilitarianism - Ethics Unwrapped. [online] Available at: $<$ https://ethicsunwrapped.utexas.edu/glossary/utilitaria nism> [Accessed 29 September 2020].

[5] University, S., 2020.Calculating Consequences: The Utilitarian Approach To Ethics. [online] Scu.edu. Available at: <https://www.scu.edu/ethics/ethics-resources/ethical-de cision-making/calculating-consequences-the-utilitarianapproach/> [Accessed 29 September 2020].

[6] Europarl.europa.eu. 2020. [online] Available at: <https://www.europarl.europa.eu/RegData/etudes/ATA G/2020/649375/EPRS_ATA(2020)649375_EN.pdf> [Accessed 10 October 2020].

[7] Orlandohealth.com. 2020.How Heat Can Trigger Asthma Symptoms. [online] Available at: <https://www.orlandohealth.com/content-hub/how-heat -can-trigger-asthma-symptoms> [Accessed 29 September 2020].

[8] World Resources Institute. 2020.Responding To Coronavirus: Low-Carbon Investments Can Help Economies Recover. [online] Available at: $<$ https://www.wri.org/blog/2020/03/coronavirus-econo my-low-carbon-investments> [Accessed 29 September 2020].

[9] HeraldScotland. 2020.Scottish Maths Expert Reveals Your Chances Of Catching Coronavirus. [online] Available at:

<https://www.heraldscotland.com/news/18327916.coro navirus-maths-expert-reveals-chances-catching-covid-1 9/> [Accessed 29 September 2020].
[10] CEBM. 2020.Is A 14-Day Quarantine Effective Against The Spread Of COVID-19? - CEBM. [online] Available at:

$<$ https://www.cebm.net/covid-19/is-a-14-day-quarantin e-effective-against-the-spread-of-covid-19/> [Accessed 29 September 2020].

[11] PollyBarks.com. 2020.Is Shopping Online More Eco-Friendly Than Shopping Local? - Pollybarks.Com. [online] Available at:

<https://pollybarks.com/is-shopping-online-more-eco-f riendly-than-shopping-local/> [Accessed 29 September 2020].

[12] EMI. 2020.CESI: SURE: AN EU PROGRAMME FOR SUPPORT TO MITIGATE UNEMPLOYMENT RISKS IN AN EMERGENCY. [online] Available at: $<$ https://europeanmovement.eu/news/cesi-sure-an-eu-pr ogramme-for-support-to-mitigate-unemployment-risksin-an-emergency/> [Accessed 29 September 2020].

[13] Statista. 2020.Topic: COVID-19: Impact On The Global Economy. [online] Available at: <https:/www.statista.com/topics/6139/covid-19-impact -on-the-global-economy/> [Accessed 29 September 2020].

[14] Voxeu.org. 2020.Economics In The Time Of COVID-19: A New Ebook|VOX, CEPR Policy Portal. [online] Available at:

<https://voxeu.org/article/economics-time-covid-19-ne w-ebook> [Accessed 10 October 2020].

[15] Voxeu.org. 2020.Economics In The Time Of COVID-19: A New Ebook | VOX, CEPR Policy Portal. [online] Available at:

<https://voxeu.org/article/economics-time-covid-19-ne w-ebook> [Accessed 10 October 2020].

[16] Clean Energy Wire. 2020. Germany'S Greenhouse Gas Emissions And Energy Transition Targets. [online] Available at:

<https://www.cleanenergywire.org/factsheets/germanys -greenhouse-gas-emissions-and-climate-targets> [Accessed 10 October 2020]. 